\title{
Landslide susceptibility mapping based on triggering factors using a multi-modal approach
}

\author{
Rouba Kaafarani ${ }^{1}$, Grace Abou-Jaoude 2,*, Joseph Wartman ${ }^{3}$, and Miriam Tawk \\ ${ }^{1}$ Graduate Student, Civil Engineering Department, Lebanese American University, Lebanon \\ ${ }^{2}$ Associate Professor, Civil Engineering Department, Lebanese American University, Lebanon \\ ${ }^{3}$ Professor, Civil and Environmental Engineering Department, University of Washington, U.S.A. \\ ${ }^{4}$ Doctoral Student, School of Civil, Mining \& Environmental Engineering, University of Wollongong, Australia
}

\begin{abstract}
Landslide susceptibility mapping has been done using statistical and physically-based assessment techniques with limited focus on mode-specific models to identify failure modes and runout patterns. Because each failure mode has different consequences, it is essential to identify the failure mode associated with each slope inclination category, triggering factor, and geological setting. This paper presents a multimodal regionalscale assessment procedure for rainfall and earthquake-induced landslides, in the country of Lebanon, where landslide inventories are not available. Three failure modes are studied: debris flows, rock-slope failures, and coherent rotational slides. Areas prone to each mode of failure are identified based on geology and topography, then, using mode-specific models, their susceptibility to landslides is assessed. A runout assessment approach is then presented to identify the influence area of each predicted landslide and to obtain comprehensive susceptibility maps. Field assessment validated the proposed model which was in good agreement with actual slope failures across Lebanon. Therefore, the multimodal approach may be used to assess rainfall-induced landslide susceptibility, especially when landslide inventories are unavailable.
\end{abstract}

\section{Introduction}

Landslides are a secondary effect of natural hazards such as earthquakes and intense storms. Because of the damage that they may cause to people, buildings and infrastructure, landslide hazard mapping on a regional scale has become essential for safe planning, disaster management, and hazard mitigation [20]. Landslide hazard or susceptibility mapping methods depend on the landslide-initiating event. Several methods such as numerical models [15] and Newmark's sliding block model [17] have been implemented in the past to generate earthquake-induced landslides susceptibility maps. Statistical methods have been used to assess rainfall-induced shallow landslides susceptibility on large scales [3,5] and empirical models have identified rainfall thresholds that trigger landslide events based on rainfall data [4, 11]. Recently, physically based models have been used, with the Geographic Information Systems, to map rainfall-induced shallow landslide susceptibility on a regional scale $[2,13,14]$.

Only few researchers employed mode-specific approaches to assess landslide susceptibility. Recently, an innovative multimodal approach was proposed to assess regional-scale co-seismic landslide hazards in the country of Lebanon [9]. The approach focused on four common types of coseismic landslides: (1) rock-slope failures, (2) disrupted soil slides, (3) coherent rotational slides, and (4) lateral spreads. It was developed for regions, like Lebanon, where landslide inventories are not available. We build upon this approach to assess the rainfall-induced landslide susceptibility in Lebanon using the available geologic, topographic, and rainfall data. We consider three failure modes for rainfall-induced landslides: (1) rock-slope failures, (2) debris flows, and (3) coherent rotational slides to identify the initiation sources. While some researchers used only these initiation sources of landslides as hazard or susceptibility zones, runout analysis has become essential to estimate the full influence extent of a slope failure. Therefore, we present also in this paper the methodology to assess the runout damage extent for rainfall and earthquake triggered landslides. Comprehensive landslide susceptibility maps are then produced. Since each failure more has a particular impact on human life, property and infrastructure systems, risk calculations can then be performed for each failure mode separately. Finally, because Lebanon lacks a landslide inventory, a field

\footnotetext{
* Corresponding author: grace.aboujaoude@lau.edu.lb
} 
verification was conducted to validate the proposed models for susceptibility and runout assessment. Results show that the mapped susceptibility and runout are in good agreement with field-verified unstable slopes. This demonstrates that the susceptibility and runout assessment models can be used for regional-scale analysis.

\section{Rainfall induced landslide susceptibility assessment: Multimodal model}

We build upon the multimodal approach presented in [9] to assess susceptibility to three types of rainfall-induced landslides on a regional scale: (1) debris flows, (2) rock slope failures, and (3) coherent rotational slides. Topographic slope and geologic formation are used to determine terrains susceptible to rainfall-induced landslides and the corresponding mode of failure. Then, a mode-specific model is used to compute either the critical daily rainfall depth needed to trigger landslides or the factor of safety of slopes based on the maximum daily rainfall depth and the associated level of saturation of these slopes. Slopes where the maximum daily rainfall depth is greater than the critical rainfall value or where the factor of safety is less than one are considered susceptible to landslides.

\subsection{Slope susceptibility}

The slope bounds adopted by [9] are used to delineate the slopes where each mode of failure is more likely to occur. Slopes from $15^{\circ}$ to $50^{\circ}$ are susceptible to debris flows. Slopes greater than $35^{\circ}$ are assessed against rock-slope failures, while terrain susceptible to coherent rotational failures is limited to slopes from $15^{\circ}$ to $35^{\circ}$, based on [1]. Terrains susceptible to coherent rotational slides are limited to slopes from $20^{\circ}$ to $35^{\circ}$. Slopes less than $15^{\circ}$ are not considered susceptible to any mode of failure under intense rainfall.

\subsection{Mode-specific rainfall susceptibility assessment}

\subsection{Debris flow}

Debris flow analysis is based on the model developed by [13] which combines a hydrological model with a limit equilibrium slope stability model to calculate the critical rainfall necessary to trigger slope instability:

$$
Q_{c r}=\frac{T \sin \theta}{\left(\frac{a}{b}\right)}\left[\frac{c^{\prime}}{\rho_{w} g z \cos ^{2} \theta \tan \varphi}+\frac{\rho_{s}}{\rho_{w}}\left(1-\frac{\tan \theta}{\tan \varphi}\right)\right]
$$

where $\mathrm{Q}_{\mathrm{cr}}$ is the critical rainfall $[\mathrm{mm} / \mathrm{d}]$, $\mathrm{T}$ is the transmissivity of soil $\left[\mathrm{m}^{2} / \mathrm{d}\right]$, a is the catchment area $\left[\mathrm{m}^{2}\right]$, b is the pixel width $[\mathrm{m}], \mathrm{c}^{\prime}$ is the root cohesion $\left[\mathrm{kN} / \mathrm{m}^{2}\right], \mathrm{g}$ is the gravitational acceleration in $\left[\mathrm{m} / \mathrm{s}^{2}\right], \mathrm{z}$ is the soil thickness [m], $\theta$ is the slope angle $[\mathrm{rad}], \varphi$ is the friction angle [rad], $\rho_{\mathrm{w}}$ is the density of water and $\rho_{\mathrm{s}}$ is the density of soil $\left[\mathrm{kg} / \mathrm{m}^{3}\right]$.

The model excludes both unconditionally unstable and unconditionally stable slopes [14], and the model is run assuming cohesionless soils, thus friction angles are increased to compensate for the absence of cohesion [13, 14]. Root cohesion can be applied as a constant value across a region or can be derived from the vegetation index.

\subsubsection{Rock slope failures}

Rock-slope failures are modelled based on Culmann wedge failure analysis [7] with water pore pressure factor is added to the equation (Fig. 1):

$$
F S=\frac{2 c \sin \theta}{\gamma h \sin (\theta-\alpha) \sin \alpha}+\frac{\tan \varphi}{\tan \alpha}-\frac{h_{w} \gamma_{w} \sin \theta \tan \varphi}{2 h \gamma \sin (\theta-\alpha) \sin \alpha}
$$

where FS is the factor of safety of the rock wedge, $\gamma$ is the unit weight of rock $\left[\mathrm{kN} / \mathrm{m}^{3}\right], \mathrm{h}$ is the height of rock face $[\mathrm{m}], \alpha$ is the failure plane angle [rad], $\theta$ is the slope angle [rad], $\varphi$ is the friction angle [rad], $\mathrm{c}$ is the cohesion $\left[\mathrm{N} / \mathrm{m}^{2}\right], \gamma_{\mathrm{w}}$ is the unit weight of water $\left[\mathrm{kN} / \mathrm{m}^{3}\right]$ and $\mathrm{h}_{\mathrm{w}}$ is the height of water $[\mathrm{m}]$.

The failure plane angle in case of rock slope failure $\alpha$ is assumed to be equal to $\frac{(\theta+\varphi)}{2}$ [19]. The height of rock face is given by " $\mathrm{h}=15 \times \tan \theta$ " where $15 \mathrm{~m}$ is the pixel size. Then, the height of water is calculated as " $\mathrm{h} \times$ saturation", where saturation is determined from available rainfall data. 


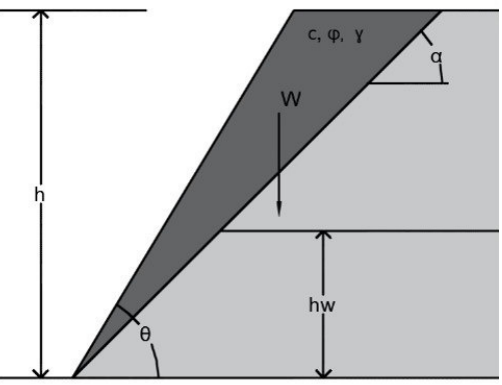

Fig. 1. Rainfall-induced rock slope failure

\subsubsection{Coherent rotational slides}

To analyze coherent rotational slides, we modified the model developed by [9] and added water pore pressure to the factor of safety equation (Fig.2):

$$
F S=\frac{c L+\left(W \cos \alpha-F_{W}\right) \tan \varphi}{W \sin \alpha}
$$

where $c$ and $\varphi$ are the cohesion [kPa] and friction angle [rad] of the soil mass, $L$ is the length of failure plane given by $L=$ $2 \delta R[\mathrm{~m}]$, and $\alpha$ is the basal angle given by $\alpha=\sin ^{-1} \frac{\left(4(\sin \delta)^{3} \sin \theta\right)}{2(2 \delta-\sin 2 \delta)}[\mathrm{rad}], W$ the weight of the sliding block given by $W=$ $\frac{\gamma R^{2}}{2}(2 \delta-\sin 2 \delta)$, and $\mathrm{F}_{\mathrm{w}}$ is the resultant force of pore water pressure given by $F_{w}=\frac{\gamma_{w} R^{2}}{2 \cos \theta}(2 \beta-\sin 2 \beta)$. The local hillslope relief is determined by moving window analysis of varying sizes. Then, the circular failure plane radius is assumed to extend to the depth of local relief, $R=\frac{H}{4}\left(\frac{\cos \beta}{1(\sin \beta)^{2}}+\frac{1}{\cos \beta}\right)[\mathrm{m}]$. The internal angle, $\delta$ is computed as $\delta=\sin ^{-1} \frac{H}{2 R \sin \beta}$ [rad] for slopes $15^{\circ} \leq \theta \leq 35^{\circ}$, and $\beta$ is determined by the level of saturation.

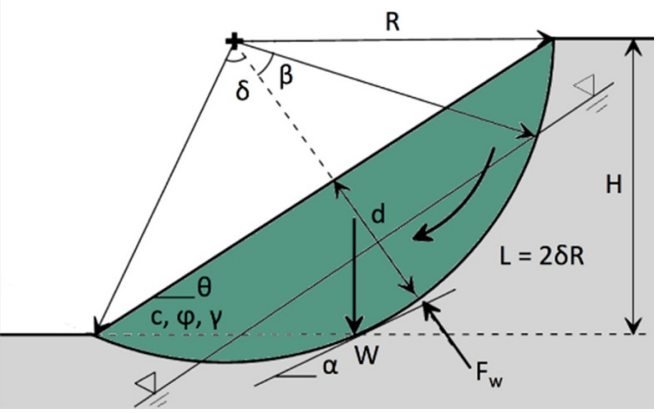

Fig. 2. Rainfall-induced coherent rotational slides

\section{Runout assessment}

A general runout analysis is developed and applied across the region. The estimation of landslide runout distances is governed by the volume, velocity and topography of the region [8]. We develop a comprehensive method that allows us to approximate the runout zones for each mode of failure. The method used is not limited to any specific triggering factor [6]. Landslide volume, which can be predicted from hazard areas by assuming the average depth of each landslide mode, is used as input. In this paper, we present how runout is assessed for rock slope failures, disrupted soils slides and debris flows only.

\subsection{Rock slope failure}


To model the runout path of earthquake and rainfall-induced rock slope failures, the "Viewshed" tool in ArcGIS is used [12]. The azimuths angles for each hazard object are determined based on the orientation of the slope and the vertical angle is based on the angle of reach proposed by [6].

\subsection{Disrupted soil slides and debris flow}

The "Steepest Path" tool in ArcGIS is employed for runout zonation associated with earthquake-induced disrupted soil slides and rainfall-induced debris flows. The results of this tool is compared with those predicted using the angle of reach for debris flows [6]. To generate the runout zones on a regional scale, the "Cost Path" tool is used, and the output is further limited since the modelled path extends to valleys and streamlines. Using the reach angles [6] and azimuths based on the direction of the slope, the Viewshed analysis is applied to limit the runout zones generated by the "Cost Path" tool.

\section{Application to Lebanon}

\subsection{Lebanon's geologic and climatic setting}

Lebanon is a small Mediterranean mountainous country with the principle geologic units being Limestone and Sandstone dating back to the Early Jurassic. It has a Mediterranean climate with hot, dry summers and cold, wet winters. About $70 \%$ of the average rainfall occurs between November and March and ranges from 0 to $1400 \mathrm{~mm} / \mathrm{year}$ [16].

\subsection{Strength parameters and rainfall data}

The model studies all geologic units and uses the same soil and rock strength parameters as in [9] to predict debris flow failures but adjusts these parameters for the wedge and coherent failure modes. For debris flow, root cohesion is derived from the vegetation index across Lebanon [18]. Transmissivity is estimated from the hydraulic conductivity in different geologic units. The unit weight of all rock materials is assigned a value of $23 \mathrm{kN} / \mathrm{m}^{3}$ (typical of limestone, sandstone and marl) while that of sand and gravel soil is taken as $20 \mathrm{kN} / \mathrm{m}^{3}$.

A map of annual average rainfall and point data of maximum daily rainfall are used to estimate the hydrologic inputs for each mode of failure. The data is linearly scaled by the average rainfall depths, creating a geographically continuous map of daily rainfall for seven return-period events.

\subsection{Rainfall landslide susceptibility}

\subsubsection{Debris Flow}

Eq. 1 is applied in GIS to compute critical rainfall required to trigger landslides. The values used in the analysis are $\mathrm{T}=25.92$, 38.8 and $51.84 \mathrm{~m}^{2} / \mathrm{day}, \mathrm{b}=15 \mathrm{~m}, \rho_{\mathrm{w}}=1000 \mathrm{~kg} / \mathrm{m}^{2}$, and $\rho_{\mathrm{s}}=20 \mathrm{~kg} / \mathrm{m}^{2}$. The catchment area is calculated using ArcGIS. According to topography, each cell either accumulates flow or directs it to another cell, but the catchment area should consider the cell itself. Thus, we generate the catchment area map by applying the following equation: $\mathrm{a}=($ Flow accumulation +1$) \times$ pixel area, where $\mathrm{a}=$ catchment area $\left[\mathrm{m}^{2}\right]$. Susceptibility zones consist of all slopes ranging from 15 to 45 degrees where the critical rainfall value generated by the model is greater than the scaled daily rainfall depth from Table 1. Fig. 3 shows the predicted debris flows in Aaquoura.

Table 1: Scaled Daily Rainfall

\begin{tabular}{cccccccc}
\hline & \multicolumn{7}{c}{ Return Period (yr) } \\
$\begin{array}{c}\text { Mean } \\
\text { Annual } \\
\text { Rainfall } \\
\text { (mm/yr) }\end{array}$ & 2 & 3 & 5 & 10 & 20 & 50 & 100 \\
\cline { 2 - 7 } & \multicolumn{7}{c}{ Scaled Daily Rainfall (mm/day) } \\
\hline 100 & 60 & 69 & 78 & 89 & 98 & 108 & 114 \\
\hline 200 & 60 & 69 & 79 & 92 & 104 & 120 & 133 \\
\hline 300 & 59 & 69 & 80 & 94 & 110 & 132 & 152 \\
\hline
\end{tabular}




\begin{tabular}{cccccccc}
\hline 400 & 58 & 68 & 80 & 97 & 116 & 145 & 171 \\
\hline 500 & 57 & 68 & 81 & 100 & 122 & 157 & 190 \\
\hline 600 & 56 & 67 & 82 & 103 & 128 & 169 & 209 \\
\hline 700 & 55 & 67 & 82 & 106 & 134 & 182 & 228 \\
\hline 800 & 54 & 67 & 83 & 109 & 140 & 194 & 247 \\
\hline 900 & 53 & 66 & 83 & 111 & 147 & 206 & 266 \\
\hline 1000 & 52 & 66 & 84 & 114 & 153 & 219 & 285 \\
\hline 1100 & 51 & 65 & 85 & 117 & 159 & 231 & 304 \\
\hline 1200 & 50 & 65 & 85 & 120 & 165 & 243 & 323 \\
\hline 1300 & 49 & 65 & 86 & 123 & 171 & 256 & 342 \\
\hline 1400 & 48 & 64 & 87 & 126 & 177 & 268 & 361
\end{tabular}

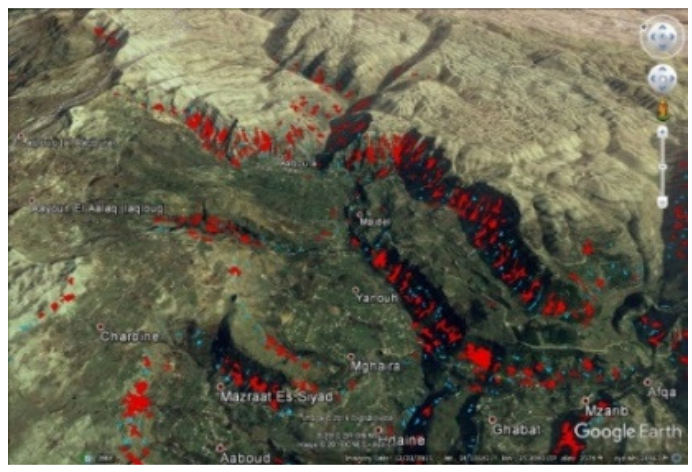

Fig. 3. Debris flows predicted in Aaquoura

\subsubsection{Rock slope failures}

Eq. 2 is used in GIS to calculate the factor of safety. The height of a rock face is given by $h=10 \times \tan \theta$, where $\theta$ is the slope angle and $10 \mathrm{~m}$ is the depth of the rock wedge. Then, the height of water is calculated as "h $\times$ saturation". Saturation is determined from the available rainfall data, and slopes having a factor of safety less than one are considered susceptible to rainfall-induced landslides. Fig. 4 shows rainfall induced rock slope failures predicted in Akkar and Jbeil.
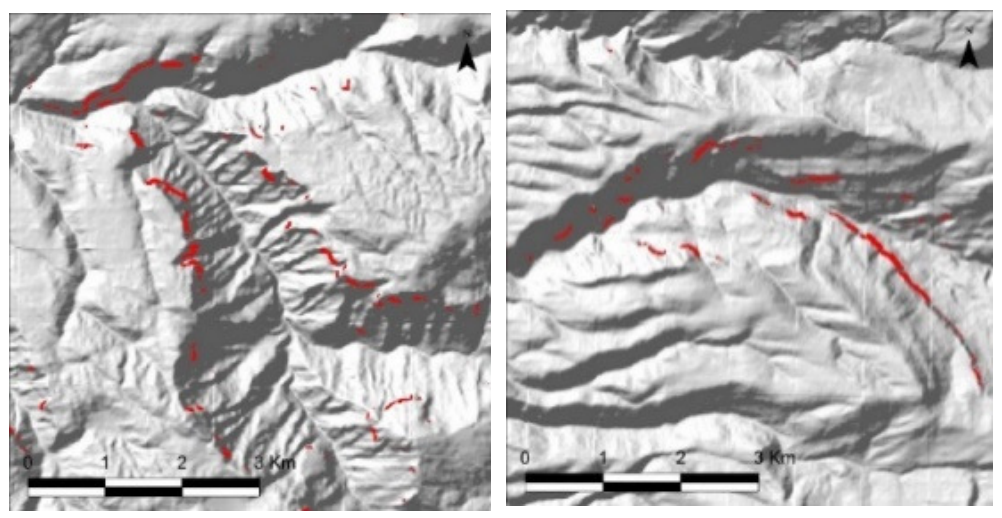

Fig. 4. Rock slope failures predicted in Akkar and Jbeil 


\subsubsection{Coherent rotational slides}

Areas prone to rainfall-induced coherent rotational slides are determined using Eq. 3. For simplicity, the ground water table is assumed to be parallel to an idealized hillslope based on local relief and located at a saturation level some percentage of the maximum failure depth, see Figure 2. The saturation level within a hillslope susceptible to rotational failure was associated to the scaled daily rainfall. In the zone of highest annual rainfall, a 100-year storm was assumed to produce $70 \%$ saturation. The levels of saturation for all other zones and return periods were linearly scaled from this maximum value (see Table 2 ).

Table 2: Saturation values for coherent rotational failures

\begin{tabular}{cccccccc}
\hline & \multicolumn{7}{c}{ Return Period (year) } \\
\cline { 2 - 8 } \begin{tabular}{c} 
Mean Annual $\begin{array}{c}\text { Sainfall } \\
\text { (mm/year) }\end{array}$ \\
\cline { 2 - 8 }
\end{tabular} & 2 & 3 & 5 & 10 & 20 & 50 & 100 \\
\hline 100 & 12 & 13 & 15 & 17 & 19 & 21 & 22 \\
\hline 200 & 12 & 13 & 15 & 18 & 20 & 23 & 26 \\
\hline 300 & 11 & 13 & 15 & 18 & 21 & 26 & 29 \\
\hline 400 & 11 & 13 & 16 & 19 & 22 & 28 & 33 \\
\hline 500 & 11 & 13 & 16 & 19 & 24 & 30 & 37 \\
\hline 600 & 11 & 13 & 16 & 20 & 25 & 33 & 41 \\
\hline 700 & 11 & 13 & 16 & 21 & 26 & 35 & 44 \\
\hline 800 & 10 & 13 & 16 & 21 & 27 & 38 & 48 \\
\hline 900 & 10 & 13 & 16 & 22 & 28 & 40 & 52 \\
\hline 1000 & 10 & 13 & 16 & 22 & 30 & 42 & 55 \\
\hline 1100 & 10 & 13 & 16 & 23 & 31 & 45 & 59 \\
\hline 1200 & 10 & 13 & 17 & 23 & 32 & 47 & 63 \\
\hline 1300 & 9 & 13 & 17 & 24 & 33 & 50 & 66 \\
\hline 1400 & 9 & 12 & 17 & 24 & 34 & 52 & 70 \\
\hline & & & & & &
\end{tabular}

\subsection{Coseismic and rainfall landslide runout zonation}

Using the "Viewshed" tool in ArcGIS and the reach angles proposed by [6], observed in the field, measured from an inventory of rock slope failures mapped in Google Earth, we determined the influence areas of coseismic and rainfall-induced rockslope failures. Volumes are estimated based on the distribution of the initiation source areas and reach angles are assigned based on them as shown in Table 3. It is assumed that under intense rainfall, debris flows tend to travel long distances following the steepest path and then merge with the drainage network [10]. Thus, the reach angle is not used to limit the runout zones. Fig. 5 shows runout zonation in Aaquoura and Litige, and Tannourine.

Table 3: Reach angles based on source area distribution

$$
\text { Mode of failure }
$$

\begin{tabular}{cccc}
\hline & \multicolumn{3}{c}{ Earthquake induced rock slope failures } \\
\hline Area $\left(\mathbf{m}^{\mathbf{3}}\right)$ & $<1000$ & $1000-5000$ & $>5000$ \\
\hline Angle of Reach & $33^{\circ}$ & $26^{\circ}$ & $26^{\circ}$ \\
\hline
\end{tabular}




\begin{tabular}{cccc}
\hline & \multicolumn{3}{c}{ Earthquake induced disrupted soil slides } \\
\hline Area $\left(\mathbf{m}^{\mathbf{3}}\right)$ & $\leq 450$ & $450-1800$ & $>1800$ \\
\hline Angle of Reach & $26^{\circ}$ & $23^{\circ}$ & $21^{\circ}$ \\
\hline \multicolumn{3}{c}{ Rainfall induced rock slope failures } \\
\hline Area $\left(\mathbf{m}^{\mathbf{3}}\right)$ & \multicolumn{4}{c}{225} & $34^{\circ}$ & $>5000$ \\
\hline Angle of Reach & $42^{\circ}$ & $34^{\circ}$ \\
\hline
\end{tabular}
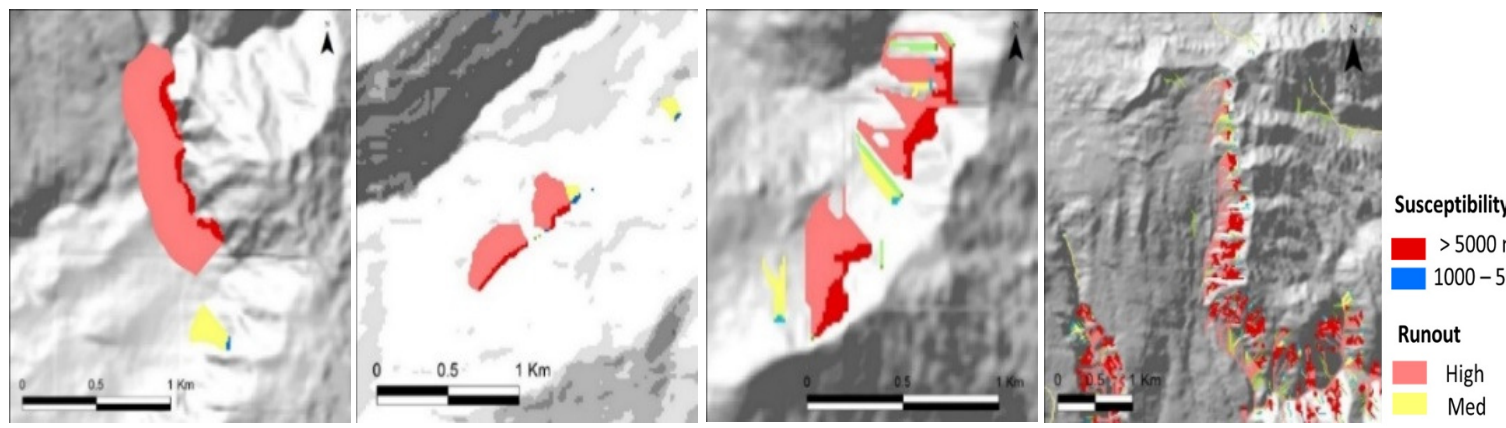

Fig. 5. (a) Earthquake-induced rock-slope failure runout in Aaquoura; (b) Rainfall-induced rock-slope failure runout in Litige; (c) Earthquake-induced disrupted soil slide runout in Tannourine; (d) Rainfall-induced debris flow runout in Aaquoura

\subsection{Field Assessment}

Following the development of the final susceptibility maps including runout, a two-day field reconnaissance campaign along the Mount Lebanon Range was done in March 2017 to validate the results. Thirty sites were examined for the three modes of failure, and the observations validated the model results. Debris flow hazard was identified along the steep slopes of the Mount Lebanon Range and coherent failures were observed in some of the predicted locations in Mount Lebanon's weak sandstone. In general, the model correctly identified terrain susceptible to different modes of failure. However, due to the lack of a comprehensive landslide database, few of the landslide deposits observed in the field were associated with a triggering event, so we were not able to assess the frequency component of the multimodal hazard model.

\section{Conclusion}

Landslide risk assessment is essential in Lebanon because landslides can pose a significant risk on human life and infrastructure. A multimodal approach tailored to assess rainfall-induced landslides on a regional scale is developed, and a corresponding methodology to assess landslide runout is proposed to be applied on a regional scale with the absence of landslide inventories. Landslide data availability can help in assessing the efficiency of the proposed models in predicting landslides and their runout zones. The proposed model and methodology are tested in Lebanon. Qualitative susceptibility maps including initiation sources of landslides and their runout zones are generated. These maps may be used for land-use assessment and suitable mitigation measures can be undertaken in high hazard zones.

\section{References}

1. Abdallah, C., Faour, G. Natural Hazards, 85 (1), 237-266 (2016)

2. Arnone, E., Noto, L., Lepore, C., Bras, R. Geomorphology, 133 (3-4), 121-131 (2011)

3. Bai, S., Wang, J., LÜ, G., Zhou, P., Hou, S., Xu, S. Pedosphere, 19 (1), 14-20 (2009)

4. Brunetti, M. T., Peruccacci, S., Rossi, M., Luciani, S., Valigi, D., Guzzetti, F. Natural Hazards and Earth System Science, 10 (3), 447-458 (2010)

5. Carrara, A., Cardinali, M., Detti, R., Guzzetti, F., Pasqui, V., Reichenbach, P. Earth Surface Processes and Landforms, 16 (5), 427-445 (1991).

6. Corominas, J., Copons, R., Vilaplana, J. M., Altimir, J., Amigó, J. Natural Hazards, 30 (3), 421-435 (2003) 
7. Duncan, J. M., Wright, S. G., Brandon, T. L. Soil Strength and Slope Stability. Hoboken: John Wiley \& Sons (2014)

8. Erener, A., Düzgün, H. B. Landslides, 10 (1), 55-73 (2012)

9. Grant, A., Wartman, J., Abou-Jaoude, G. Engineering Geology, 212, 146-160 (2016)

10. Guinau, M., Vilajosana, I., Vilaplana, J. M. Natural Hazards and Earth System Science, 7 (6), $703-716$ (2007).

11. Guzzetti, F., Peruccacci, S., Rossi, M., Stark, C. P. Landslides, 5 (1), 3-17 (2007)

12. Heron, D., Lukovic, B., Massey, C., Ries, W., McSaveney, M. Christchurch. Journal of Spatial Science, 59 (2), $313-332$ (2014)

13. Montgomery, D. R., Dietrich, W. E. Water Resources Research, 30 (4), 1153-1171 (1994)

14. Montgomery, D. R., Sullivan, K., Greenberg, H. M. Hydrological Processes, 12 (6), 943-955 (1998)

15. Mousavi, S. M., Omidvar, B., Ghazban, F., Feyzi, R. Engineering Geology, 122 (3-4), 191-203 (2011)

16. Plassard, J. Carte pluviométrique du Liban à l'échelle de 1.200.000. République Libanaise. Ministère des travaux publics. Direction Générale de l'Aviation Civile (1971)

17. Saade, A., Abou-Jaoude, G., Wartman, J., Grant, A. Geo-Chicago (pp. 177-186) (2016)

18. Schmidt, K.M., Roering, J.J., Stock, J.D., Dietrich, W.E., Montgomery, D.R., Schaub, T. Can. Geotech. J. 28 (5). $995-$ 1024 (2001)

19. Wyllie, D. C., \& Mah, C. W. Rock Slope Engineering: Civil and Mining (4th Ed.). London: Spon Press (2004)

20. Xu, C., Xu, X., Dai, F., Saraf, A. K. Computers \& Geosciences, 46, 317-329 (2012) 